\title{
Applying an invasion and risk framework to track non- native island floras: a case study of challenges and solutions in Hawai'i
}

\author{
Kelsey C. Brock', Curtis C. Daehler' \\ I University of Hawai i-Manoa, School of Life Sciences, Honolulu, Hawai i, USA \\ Corresponding author: Kelsey C. Brock (kcbrock@hawaii.edu)
}

Academic editor: J. R. Wilson | Received 31 March 2020 | Accepted 26 June 2020 | Published 15 October 2020

Citation: Brock KC, Daehler CC (2020) Applying an invasion and risk framework to track non-native island floras: a case study of challenges and solutions in Hawai'i. In: Wilson JR, Bacher S, Daehler CC, Groom QJ, Kumschick S, Lockwood JL, Robinson TB, Zengeya TA, Richardson DM (Eds) Frameworks used in Invasion Science. NeoBiota 62: 55-79. https://doi.org/10.3897/neobiota.62.52764

\begin{abstract}
Islands are plant invasion hotspots, with some having more non-native than native species. Many plants are recent arrivals, leading to concerns that their full spread and impacts are not yet realised. Given that islands host extraordinary numbers of endemic and threatened species, schemes are urgently needed to track the complex, species-rich but data-poor scenarios typical of islands. This study applies the unified framework by Blackburn et al. (2011) for categorising invasion stages to Hawai'i's non-native plant checklist and identifies potential uses and complications for species tracking and invasion management. Data deficiencies and ambiguities required lumping Blackburn et al.'s categories to align with Hawai'i’s available data; nonetheless, this coarser categorisation describes invasion phases relevant to managers and could provide the basis for an effective tracking system. However, the unified framework does not accommodate uncertain invasion statuses, which prevents clear categorisation of species that exist outside of cultivation but are not definitely naturalised. In response to this obstacle, scores from the Hawai i-Pacific Weed Risk Assessment (WRA) are explored to understand their application for predicting naturalisation, including standard WRA scores as well as alternative scoring methods. We show that this predictive tool may be a promising supplement to on-the-ground monitoring for data-deficient elements of a flora. Finally, a categorisation system for tracking statuses of an entire non-native flora is proposed that requires limited investments in additional data collection while following the rationale of Blackburn et al.'s scheme. This categorisation system may be used to reveal overall invasion patterns and trends in a region, leading to valuable insights into strategies for biodiversity management and conservation.
\end{abstract}

\section{Keywords}

Biodiversity monitoring, flora, invasion framework, invasion tracking, invasive plants, naturalisation, species checklist, weed risk assessment

Copyright Kelsey C. Brock, Curtis C. Daehler. This is an open access article distributed under the terms of the Creative Commons Attribution License (CC BY 4.0), which permits unrestricted use, distribution, and reproduction in any medium, provided the original author and source are credited. 


\section{Introduction}

Oceanic islands have long been considered highly invasible, hosting higher ratios of native to non-native richness per area than climatically comparable mainland regions (Lonsdale 1999; Sax and Gaines 2008). Around 40\% of island floras are now composed of at least $40 \%$ non-native species (Pyšek et al. 2017). These trends are particularly alarming because remote islands are hotspots of endemism, with more than a quarter of all plant species native to islands (Kier et al. 2009). Naturalisations thus far greatly exceed extinctions reported on islands, although many naturalisations are too recent for their impacts to be fully realised and even historical ones are unlikely to have spread throughout their available habitats yet (Sax and Gaines 2008). These trends indicate a potential "extinction debt" that may be paid against island endemics in the future (Kuussaari et al. 2009; Gilbert and Levine 2013).

Uncertainty of impacts from numerous naturalised species, especially on remote islands with unique endemic taxa, severely complicates management strategies. Conservation decision-making is often based on the precautionary principle, a central concept which proposes that actions taken to prevent known negative consequences should also be applied to scenarios where negative consequences are possible, but uncertain (Cooney 2004). In an information-deficient context, the precautionary principle compels conservation biologists to treat all non-native species as if they will inflict negative impacts (a.k.a. "guilty until proven innocent"). Applying this strategy to scenarios where a thousand or more potential invaders exist is unrealistic, as conservation resources are limited; thus, managers are forced to select control targets based on few data and often rely on reports of invasive behaviour elsewhere. Although invasion history is critical for assessing risk, Kueffer et al. (2010) show that problematic species on one island are not necessarily problematic on all, or even most, islands where they are present. Furthermore, invasions of new species without invasive histories continue to be reported worldwide (Seebens et al. 2017). Thus, relying on either a precautionary principle or "bad apple" approach alone could incur high costs, resulting in inefficient and ultimately ineffective conservation of threatened native species and ecosystems.

Given that non-native species are frequently established on islands and that their behaviour over time is uncertain, two approaches are needed to provide the basis for evaluating current and future impacts: 1) tracking non-native species along the introduction-naturalisation-invasion continuum and 2) predicting the likelihood of naturalisation and invasion when field data are sparse or temporally limited (Wilson et al. 2014, 2018). While the latter has attracted significant attention, the former has been tremendously under-appreciated (Hulme 2006), leaving many regions ill-equipped to manage the ever-increasing non-native portion of their floras. Characterising the phase and extent of an invasion is critical for assessing control feasibility. Monitoring alreadyintroduced species is also necessary to fine-tune predictive tools and catch species that invariably defy expectations. For many regions, the monitoring of non-native species begins with checklists of plants that have naturalised, often from data collected for floristic projects (Pyšek et al. 2004). However, some checklists further categorise species, 
distinguishing between invasive versus naturalised, old versus newer introductions and/ or noting species for which data are deficient (Pyšek et al. 2002; Galasso et al. 2018; Imada 2019). Checklists of cultivated species that are not necessarily naturalised have been compiled for some regions, but are rarer (Danihelka et al. 2012). Conservation workers may mistakenly use these checklists as tracking systems, but these lists merely describe snapshots of non-native populations when they were reported. Such surveys may be incomplete and may be several decades old. Given that many introductions are recent and statuses of these plants may change rapidly, supplementing checklists with additional data to track the invasion process is essential (Wilson et al. 2014).

Nearly three decades' worth of work to characterise the invasion process worldwide and across taxa has culminated in a unified framework proposed by Blackburn et al. (2011). The system they proposed, hereon referred to as "the unified framework", uses 11 categories to describe non-native populations by their phase of invasion, thereby providing a method for tracking statuses. These categories describe a population's progress beginning with transport and introduction through establishment and spread, which correspond to six sequential barriers to invasion success: geography, captivity/cultivation, survival, reproduction, dispersal and environment. Furthermore, categories also describe between-barrier details (e.g. B1-B3 refer to explicit, limited and no measures of containment in place, respectively); an inability to breach any one of these barriers amounts to invasion failure (Blackburn et al. 2011). If population statuses are updated frequently enough, this system can be used in conjunction with measures of commonness and distribution to help invasive species managers prioritise targets for control (McGeoch and Latombe 2016; Wilson et al. 2018). Wilson et al. (2014) outlined the unified framework's application for monitoring the status of invasive trees globally and it was successfully applied to assess Acacia and Melaleuca in South Africa, yielding categories on which to base management decisions (Jacobs et al. 2017; Magona et al. 2018). However, no study has assessed the unified framework's applicability to track an entire non-native flora, including data deficient and cultivated species. Consistent categorisation across species and over time for a region allows assessment of invasion trends, which can then be used to suggest broader scale approaches to invasion management.

The Hawaiian archipelago is an excellent model to assess methods for invasion tracking and prediction as $>55 \%$ of the total terrestrial vascular flora is comprised of naturalised species (Imada 2012, 2019; Ranker 2016; Price and Wagner 2018). As such, Hawai' $i$ offers copious examples of both well-established and newly-naturalised species to test theoretical and practical aspects of applying invasion frameworks. This includes over 1,600 naturalised and possibly naturalised species, with all but 25 thought to be introduced after the year 1778 (European contact) and more than 600 species reported in the last 30 years (Imada 2019). The need to track and mitigate impacts from non-native plants is urgent. The IUCN lists $35 \%$ of Hawai i's native flora as threatened, although this is very likely an underestimate as less than half of species have been assessed according to these international criteria (IUCN 2020a). Hawai' $i$ is also an ideal location to evaluate invasion frameworks because an active community of botanists regularly produces reports of new species, contributing to manuals of both flowering 
plants and ferns that include non-native species (Wagner et al. 1999; Palmer 2003), as well as a periodically updated checklist of naturalised plants (Imada 2019). Moreover, Hawai' $i$ utilises a predictive framework known as the Hawai i-Pacific Weed Risk Assessment (WRA) that has evaluated over 2,000 species and is used to discourage the planting of high risk plants and identify low risk alternatives, as well as to inform managers of potential control targets (Kueffer and Loope 2009). A test of this system indicated that it is $95 \%$ successful in predicting major pests that were identified by expert opinion (Daehler et al. 2004). The Hawai i-Pacific WRA assigns risk rankings ("Low Risk", "High Risk" and an uncertain "Evaluate" category) by calculating a numerical score based on 49 questions about a plant's biology, which can be divided into 35 questions pertaining to the likelihood that a plant will spread and 14 pertaining to the consequences of their spread (Daehler et al. 2004; Daehler and Virtue 2010). Although weed risk assessment (WRA) is most often highlighted as a tool to prevent harmful introductions, the resulting WRA dataset may also be useful for predicting the progress of already-introduced species along the introduction-naturalisation-invasion continuum.

In this study, we assess the viability of applying the unified framework proposed by Blackburn et al. (2011) to a checklist of non-native plants for the Hawaiian Islands and discuss its applicability for tracking invasions in Hawai' $i$. For data-deficient species whose invasion phase cannot be confidently determined from field data, we assess the potential for the Hawai i-Pacific WRA to infer the naturalisation category to which they might belong. Finally, we propose a modified set of categories based on the unified framework that are relevant for making management decisions and can accommodate data deficiencies, such as those commonly observed in Hawai' i.

\section{Methods}

\section{Aligning the naturalised species checklist}

The Bishop Museum's checklist of naturalised plants (Imada 2019) provided the main list of species for alignment with the population tracking categories outlined in Blackburn et al. (2011). This checklist tallies species that have naturalised or questionably naturalised on any island in the Hawaiian archipelago, including eight main islands (Ni'ihau, Kaua 'i, O'ahu, Molokai, Lānai, Maui, Kaho'olawe, Hawai'i) ranging in maximum elevation from 380-4,200 $\mathrm{m}$ above sea level and 11 small, sparsely vegetated islands and atolls, ranging from a few to $259 \mathrm{~m}$ above sea level (Kure, Midway, Pearl and Hermes, Lisianski, Laysan, Gardner Pinnacles, French Frigate Shoals, Necker, Nihoa, Kaula Rock, Lehua). The checklist sorts non-native species into five categories describing whether they are a Polynesian or post-European introduction and whether there is uncertainty regarding a species' introduction or naturalisation status.

We additionally reviewed naturalisation reports and herbarium specimen labels, supplementing the checklist by Imada (2019) to include recent naturalisations and re-categorising records that explicitly did not match the definition of naturalised. 
We define naturalised as non-native plants that survive and reproduce consistently to sustain populations outside of cultivation over many generations without human aid (Richardson et al. 2000; Pyšek et al. 2004), corresponding to categories C3-onwards in the unified framework (Blackburn et al. 2011). Species not meeting these criteria were downgraded from "naturalised" to the "questionably naturalised" category in the checklist of naturalised plants (Imada 2019), defined as "species not confirmed to be naturalised, including present-day adventive and escaped plants or historical collections not recently vouchered." Ultimately, the compiled checklist used in our analyses included 1,668 species that have been collected outside of cultivation on at least one of the Hawaiian Islands.

For each island, we summed the number of species in each of the following two categories: "naturalised" (including pre-European introductions by Polynesians) and "questionably naturalised" for the remaining species that could not be clearly categorised after considering available data and criteria in the unified framework. We then attempted to align species in these two groups, as well as non-naturalised cultivated species in Hawai i, with the unified framework categories. We highlighted specific examples of challenges encountered when applying the unified framework across a flora and assessed whether it is valuable for improving non-native plant species tracking and management in Hawai' $\mathrm{i}$ and elsewhere. Subsequently, we constructed a modified categorisation scheme that accommodates the data deficiencies found in Hawai'i's non-native flora.

\section{Potential for Weed Risk Assessment scores to predict naturalisation}

To determine whether the Hawai'i-Pacific WRA score or components of that score might be useful for inferring the status of "questionably naturalised" species, we examined the distribution of WRA scores amongst known naturalised species versus non-naturalised cultivated species. We also assessed the correlation between WRA score and number of islands where a species is known to be naturalised. The WRA scores were additionally separated into components related to likelihood of spread and potential consequences of impact, creating two independent scores for each species, following Daehler and Virtue (2010). Amongst 2,037 WRAs available for analysis (HPWRA 2019), we tested the hypothesis that the full WRA score or the likelihood-of-spread component of the WRA score (hereon referred to as "likelihoodonly score") can predict naturalisation by comparing the scores of plants that have naturalised with those that were introduced, but have not naturalised. The latter species were identified by cross-referencing a list of plants reported from cultivation assembled by Imada et al. (2000), supplemented by approximately 600 species known from cultivation, based on herbarium vouchers. We excluded species that are thought to be very uncommon in cultivation, such as those known from a single collection in a botanical garden, as well as species that are likely held captive in aquaria and have little chance to escape (Staples and Herbst 2005). We also removed possible recent introductions (384 species) first reported in cultivation during the last 20 years 
because the behaviour of these species is uncertain. A previous study found that lag times averaged less than 20 years between first planting and signs of naturalisation in Hawai i (Daehler 2009; see also Schmidt and Drake 2011). Data on time since first cultivation were too unreliable to investigate longer lag periods, but for a few highscoring species that had not naturalised, we checked herbarium records to make sure they were not first recorded slightly earlier (20-40 years ago).

We conducted statistical analyses with the Python library SciPy 1.0 (Virtanen et al. 2020), visualised with seaborn 0.10.0 (Waskom et al. 2020). We used Welch's $t$-test to determine whether naturalised and non-naturalised species had significantly different WRA scores and likelihood-only scores. Finally, to see if scores are related to a species' potential to spread throughout the archipelago, we compared the WRA and likelihoodonly scores to the number of islands naturalised for each plant species. These subsets of the data had non-normal distribution, so we calculated the strength of the correlation with the non-parametric Kendall's $\tau_{b}$ coefficient. The R package mblm (Komsta 2019) enabled us to visualise the linear trend between these variables with the Theil-Sen estimator, which was developed to reflect the strength of Kendall's $\tau_{b}$ (Sen 1968; Wilcox 2010). Kendall's $\tau_{b}$ is rank-based and the associated Theil-Sen estimator is derived from the median slope of pairwise data (Sen 1968). Island counts were restricted to the main Hawaiian Islands minus $\mathrm{Ni}$ i ihau, as these are more frequently surveyed and support more variable habitats in comparison to the low elevation islands in the north-western section of the archipelago (Larrue et al. 2018).

\section{Results}

\section{Alignment between the checklist and the unified framework}

\section{Cultivated species}

More than 7,300 cultivated species have been reported in Hawai' $i$, although data describing the circumstances of their containment are often lacking so that they cannot be finely categorised according to the unified framework. Thus, plants that are cultivated in Hawai' $i$ but are not naturalised were roughly aligned to the lumped categories B1 (in captivity or quarantine) and B2 (in cultivation; Fig. 1). Examples of B1 species may include houseplants that are only planted indoors, which may be less common in Hawai' $i$ than in temperate areas due to Hawai'i's tropical climate. Falling into this category are also valuable orchid species grown by hobbyists in controlled environments, such as terraria or greenhouses. We inferred that most common ornamentals and food plants would belong to category B2, where species are planted in suitable conditions with limited intentional measures to restrict their dispersal (e.g. some incidental control or limitation through landscaping activities). No species were thought to match categories $\mathrm{B} 3$ or $\mathrm{C} 0$, although examples from Hawai i likely exist that are not readily added to checklists because they are not currently present. For instance, forestry planting records indicate that Juglans nigra (black walnut) was planted to assess its suitability 

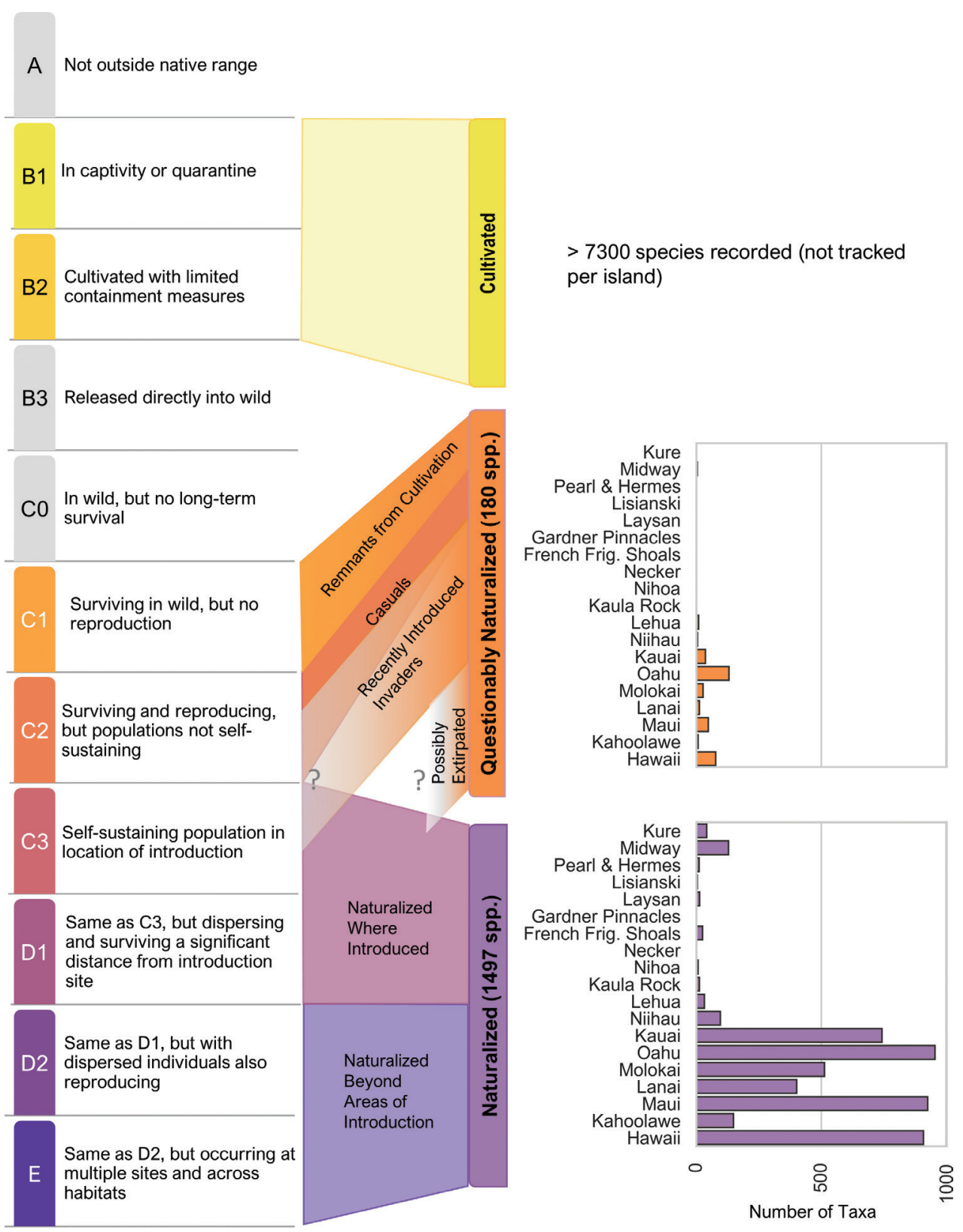

Figure I. Alignment of Blackburn et al. (2011) scheme with categories in Hawai' i's non-native species checklist. Bar graphs depict counts of species that are considered "Naturalised" (purple) and "Questionably Naturalised" (orange) in Hawai i per island, with state-wide totals next to checklist status names. Coloured polygons represent alignment or misalignment with the recommended categories. Full descriptions of Blackburn et al. (2011) categories are available in Table 2.

as a timber crop, but growth trials determined that its survivability was very low in Hawai'i (C0) (Nelson and Schubert 1976). Although category B3 is thought to apply 
to most accidental introductions that are not yet reproducing outside of cultivation (Blackburn et al. 2011), we included contaminants of horticulture in category B2 if some measure of containment is evident (e.g. existing in potting soil imported with an intentionally-cultivated plant).

\section{Questionably naturalised species}

We considered 180 species to be "questionably naturalised" at the state-wide level, amounting to 342 per-island introductions being classified in this checklist category. Based on our review of Hawai i's records and recommended terminology for conceptualising plant invasions (Richardson et al. 2000; Pyšek et al. 2004), the "questionably naturalised" category likely contains five distinct classes of species for which there are insufficient data to separate, including: 1) remnants of cultivation, such as long-lived species that were planted some time ago, but where growth of surrounding vegetation masks evidence that the site was formerly cultivated; 2) casual species, where immature or perhaps a few mature individuals originating from cultivated plants may exist outside of cultivation, but for which multiple generations are not produced (i.e. population not self-sustaining); 3) recently introduced invaders that will eventually naturalise, but have not had sufficient time to do so; 4) species that have already naturalised, but only a few individuals have been detected (i.e. current sampling is insufficient to confidently categorise populations that are actually naturalised); and 5) possibly extirpated species, for which historical records indicate that they existed outside of cultivation at one time, but have not been observed for many decades (Fig. 1).

Remnants from cultivation may arise when homesteads or forestry plots are no longer maintained, making it difficult to determine whether a species is a $\mathrm{C} 1$ (outside of cultivation, but not reproducing) or a mature individual of a naturalised population, especially if no historical planting data exist. An example of $\mathrm{C} 1$ species that may appear as naturalised in the field without prior knowledge of their planting history includes approximately 30 species of Ficus that were planted on forest reserves without the introduction of their specific pollinator wasp (Skolmen 1980). Casuals would theoretically align to category $\mathrm{C} 2$, but in practice, they are particularly difficult to distinguish from recently-introduced invaders, as was also noted by Wilson et al. (2014) when describing tree invasions. This uncertainty arises because both categories may initially appear in the field as offspring from a single or few age classes, with the distance from the originally-introduced plant dependent on its mode of dispersal (e.g. wind, gravity or bird-dispersed), rather than its potential to naturalise. One example of a species in Hawai' $i$ that fits the C2 category is Sequoia sempervirens (California redwood), for which more than 130,000 individuals were planted before 1960 (Nelson and Schubert 1976; Skolmen 1980). These plantings have been observed producing seedlings, but they have failed to mature beyond the seedling stage, even after $60+$ years and, thus, would likely vanish from the islands if the initial plantings were removed.

Although we currently lack data to distinguish recently introduced invaders from the rest of the "questionably naturalised" group on the checklist, we were conceptually 
unable to determine to which framework category these species would belong, even if they could be identified. Recently-introduced species do not appear to belong to category C3, as they do not yet form self-sustaining populations with multiple generations, but nor do they align with category $\mathrm{C} 2$, for which self-sustaining populations will never be formed.

\section{Naturalised species}

Of the 1,668 species in our checklist of plants growing outside of cultivation, 1,473 are considered naturalised in Hawai' $i$. However, these species are not uniformly naturalised across all islands, with no island containing naturalised populations of all these species. Considering each naturalisation event separately per island, we counted 4,970 instances by summing the number of naturalisations from all islands. The checklist does not provide information on dispersal and formation of new populations, as needed to distinguish between the last four categories of the unified framework and, thus, the "naturalised" category aligns broadly with C3-E (Fig. 1). On the other hand, the checklist (Imada 2019) does provide information on the number of islands where each species has naturalised. This information is potentially useful for understanding invasions across island regions; however, the unified framework does not provide an additional category for species that have naturalised or invaded across multiple geopolitical boundaries. Thus, these species are lumped in the same category with single-island species.

\section{Relationship between WRA score and naturalisation}

The Hawai'i-Pacific WRA dataset included 828 non-naturalised and 712 naturalised species after questionably naturalised and recently-introduced non-naturalised species were removed (Fig. 2). Differences in likelihood-only scores between naturalised $(\bar{x}=3.91$, $\mathrm{SD}=4.25)$ and non-naturalised $(\bar{x}=0.23, \mathrm{SD}=3.49)$ plants were significant (Welch's $t=18.40, \mathrm{df}=1376.54, p<0.001)$. Scores were also significantly different between these groups using the standard WRA scoring method (Welch's $t=27.93, \mathrm{df}=1303.27$, $p<0.001)$, but with more separation between the distributions of scores for naturalised $(\bar{x}=10.41, \mathrm{SD}=6.90)$ and non-naturalised species $(\bar{x}=1.60 \mathrm{SD}=5.17)$ compared to likelihood-only scores. Thus, the standard WRA scoring method differentiates naturalised and non-naturalised species better than likelihood-only scores, making it more useful for inferring the likely status of data-deficient species (Daehler and Virtue 2010).

Only $11 \%$ of the 436 species with WRA scores less than 1 are naturalised in Hawai $i$, which is the upper threshold score used by the Hawai i-Pacific WRA to designate species as "Low Risk" (Fig. 2). Lowering the scoring threshold from 0 to -3 for predicting nonnaturalised species decreases the error rate by only $1 \%$ (to $10 \%$ out of 201 species). On the other hand, $78 \%$ of the 684 species scoring greater than 6 (the threshold used by the WRA to deem a plant "High Risk") were naturalised. Increasing the threshold score to 12 (including 321 species) is required to increase the representation of naturalised species to $90 \%$. 

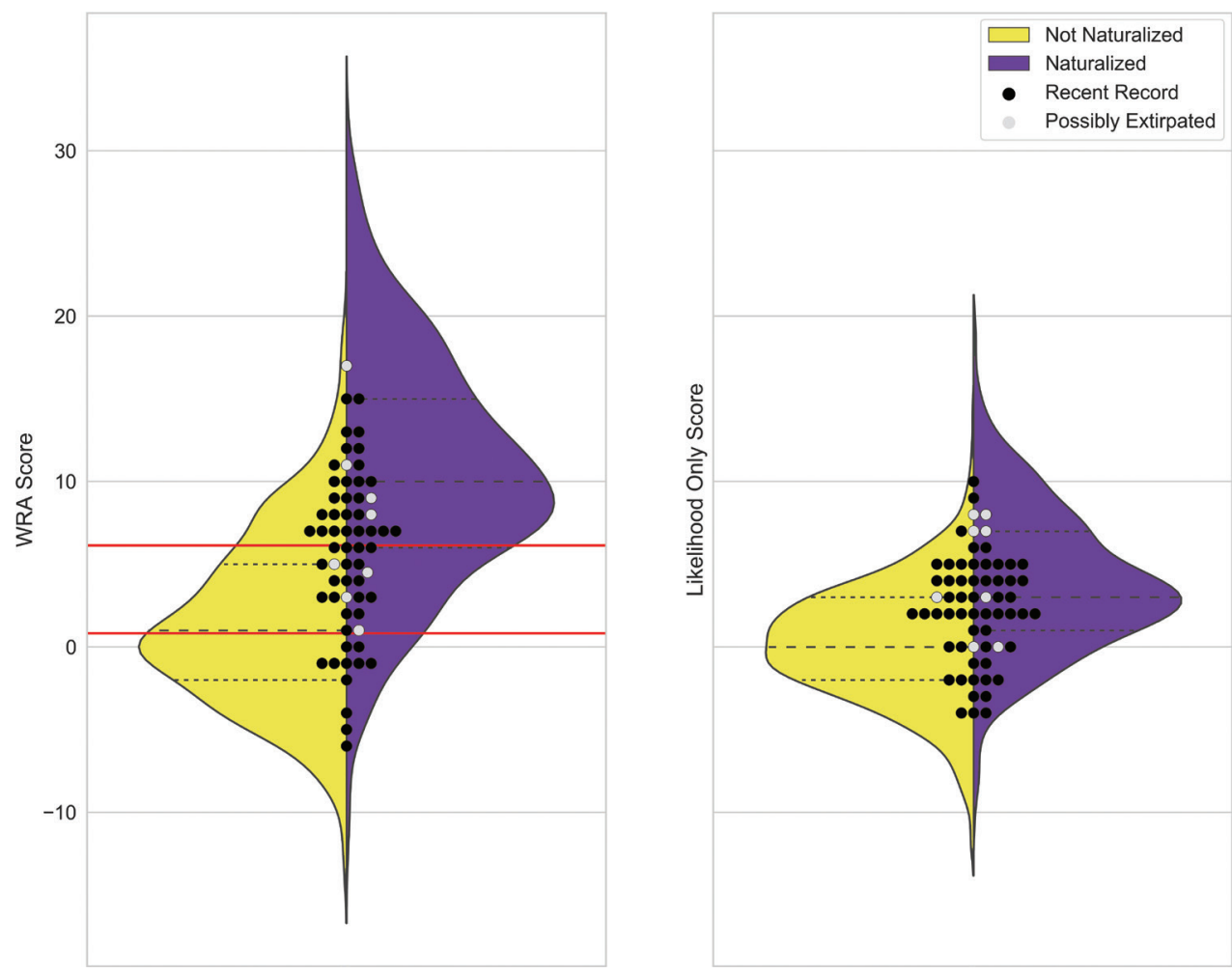

Figure 2. Distribution of non-naturalised (yellow) and naturalised (purple) scores based on WRA (left) and likelihood-only scoring (right). Dotted lines represent the lower quartile, median and upper quartile while thick solid red lines represent the scoring threshold used by the Hawai i-Pacific WRA for designating species as high risk $(>6)$ and low risk $(<1)$. Dots represent scores for "Questionably Naturalised" species; grey = possibly extirpated, black = recently observed.

The WRA score and likelihood-only score were significantly positively correlated with the number of islands on which a plant has naturalised ( $p<0.001$ for both). The trend was weak in both cases, although we observed a more positive correlation for the standard WRA score than the likelihood-only score (Kendall's $\tau_{b}=0.27$ versus 0.14 , respectively; Fig. 3).

\section{Predicting the fate of questionably naturalised species}

Sixty-three of the 180 "questionably naturalised" species state-wide have been assessed by the Hawai i-Pacific WRA (Table 1), for which we used WRA scores to infer naturalisation status. We did not consider island-specific "questionably naturalised" species that have definitely naturalised on another island in the archipelago because these species have already demonstrated the ability to successfully naturalise in Hawai $i$. After removing eight possibly extirpated species that have not been observed in more than 

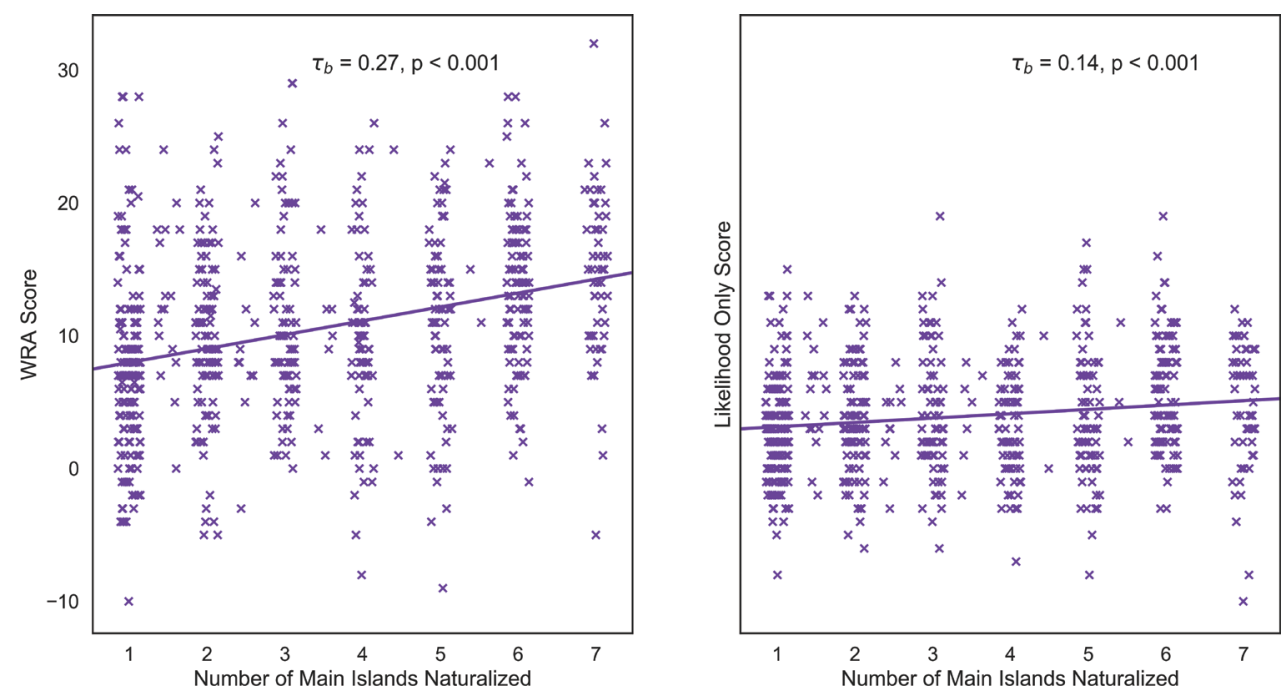

Figure 3. Relationship between the number of Hawaiian Islands naturalised with WRA (left) and likelihood-only scores (right). The fitted Theil-Sen estimator line is shown with Kendall's $\tau_{b}$ and associated $p$-value.

50 years or whose population declines have been closely monitored (based on herbarium specimens and expert opinion), 55 species remain in the data-deficient "questionably naturalised" category.

Based on the aforementioned relationship between WRA scores and naturalisation, we find that 11 species have scores $<1$ and therefore $89 \%$ of these are expected to not naturalise (Fig. 2; Table 1). Reducing the threshold to -3 narrows the pool of questionably naturalised species to only three species and there is almost no change in the expected rate of not naturalising amongst the three plant species in this group (90\%). Conversely, our data indicate that $78 \%$ of the 27 questionably naturalised species with scores greater than 6 (Fig. 2) are either naturalised already or will become naturalised. Raising this threshold to 12 identifies a set of only six species, $90 \%$ of which are likely to become naturalised.

\section{Discussion}

Our whole-flora analysis identified 342 cases where naturalisation status is currently uncertain, emphasising the need for effective tracking of non-native populations in the Hawaiian Islands. Hawai i's current checklist (Imada 2019) forms the foundation for a future tracking system, but our attempt to align it to Blackburn et al.'s unified framework (2011) revealed both benefits and drawbacks of the unified framework in handling real-world data. Species listed as "questionably naturalised" proved problematic and, although the Hawai' i-Pacific WRA may assist with categorising these species, adjustments to the unified framework are needed to create a usable system. Based on Hawai'i's non- 
Table I. Species in the "Questionably Naturalised" checklist category alongside their likely status category derived from WRA scores and time since last observation.

\begin{tabular}{|c|c|c|c|c|}
\hline Family & Species Name & WRA score & WRA rating & Likely Status* \\
\hline Fabaceae & Lespedeza cuneata (Dum. Cours.) G.Don & 17 & High Risk & Extirpated \\
\hline Apiaceae & Eryngium foetidum $\mathrm{L}$. & 15 & High Risk & Naturalised-Unspecified \\
\hline Asteraceae & Tithonia rotundifolia (Mill.) S.F.Blake & 15 & High Risk & Naturalised-Unspecified \\
\hline Menispermaceae & Stephania japonica (Thunb.) Miers & 13 & High Risk & Naturalised-Unspecified \\
\hline Tamaricaceae & Tamarix aphylla (L.) H.Karst. & 13 & High Risk & Naturalised-Unspecified \\
\hline Cannabaceae & Cannabis sativa subsp. indica (Lam.) E.Small \& Conquist & 12 & High Risk & Naturalised-Unspecified \\
\hline Bromeliaceae & Tillandsia usneoides (L.) L. & 12 & High Risk & Naturalised-Unspecified \\
\hline Asparagaceae & Asparagus falcatus $\mathrm{L}$. & 11 & High Risk & Naturalised-Unspecified \\
\hline Poaceae & Lamarckia aurea (L.) Moench & 11 & High Risk & Naturalised-Unspecified \\
\hline Poaceae & Panicum virgatum $\mathrm{L}$. & 11 & High Risk & Extirpated \\
\hline Acanthaceae & Barleria lupulina Lindl. & 10 & High Risk & Naturalised-Unspecified \\
\hline Begoniaceae & Begonia nelumbiifolia Schltdl \& Cham. & 10 & High Risk & Naturalised-Unspecified \\
\hline Combretaceae & Quisqualis indica $\mathrm{L}$. & 10 & High Risk & Naturalised-Unspecified \\
\hline Urticaceae & Laportea aestuans (L.) Chew & 10 & High Risk & Naturalised-Unspecified \\
\hline Sapindaceae & Allophylus cobbe (L.) Raeusch. & 9 & High Risk & Naturalised-Unspecified \\
\hline Iridaceae & Sisyrinchium rosulatum E.P.Bicknell & 9 & High Risk & Extirpated \\
\hline Orchidaceae & Vanilla planifolia Jacks. & 9 & High Risk & Naturalised-Unspecified \\
\hline Rhamnaceae & Ziziphus mauritiana Lam. & 9 & High Risk & Naturalised-Unspecified \\
\hline Fabaceae & Acacia retinodes Schltdl. & 8 & High Risk & Naturalised-Unspecified \\
\hline Apocynaceae & Allamanda schottii Pohl & 8 & High Risk & Naturalised-Unspecified \\
\hline Primulaceae & Ardisia virens Kurz & 8 & High Risk & Naturalised-Unspecified \\
\hline Poaceae & Echinochloa esculenta (A.Braun) H.Scholz & 8 & High Risk & Extirpated \\
\hline Vitaceae & Tetrastigma voinieranum (Baltet) Pierre ex Gagnep. & 8 & High Risk & Naturalised-Unspecified \\
\hline Fabaceae & Acacia robusta Burch. subsp. clavigera (E.Mey.) Brenan & 7 & High Risk & Naturalised-Unspecified \\
\hline Bromeliaceae & Aechmea bracteata (Sw.) Griseb. & 7 & High Risk & Naturalised-Unspecified \\
\hline Primulaceae & Ardisia sieboldii Miq. & 7 & High Risk & Naturalised-Unspecified \\
\hline Scrophulariaceae & Buddleja paniculata Wall. & 7 & High Risk & Naturalised-Unspecified \\
\hline Poaceae & Cenchrus elegans (Hassk.) Veldk. & 7 & High Risk & Naturalised-Unspecified \\
\hline Poaceae & Melinis nerviglumis (Franch.) Zizka & 7 & High Risk & Naturalised-Unspecified \\
\hline Marcgraviaceae & Norantea guianensis (Aubl.) & 7 & High Risk & Naturalised-Unspecified \\
\hline Pinaceae & Pinus pinaster Aiton & 7 & High Risk & Naturalised-Unspecified \\
\hline Apocynaceae & Acokanthera schimperi (A.DC.) Schweinf. & 6 & Evaluate & Data Deficient \\
\hline Polygonaceae & Homalocladium platycladum (F.Muell.) L.H.Bailey & 6 & Evaluate & Data Deficient \\
\hline Fabaceae & Platymiscium stipulare Benth. & 6 & Evaluate & Data Deficient \\
\hline Lamiaceae & Clerodendrum myricoides (Hochst.) Vatke & 6 & High Risk & Data Deficient \\
\hline Bignoniaceae & Markhamia lutea (Benth.) K.Schum. & 5 & High Risk & Data Deficient \\
\hline Plantaginaceae & Maurandya antirrhiniflora Humb. \& Bonpl. ex Willd. & 5 & Evaluate & Extirpated \\
\hline Aizoaceae & Mesembryanthemum cordifolium L.f. & 5 & Low Risk & Data Deficient \\
\hline Fabaceae & Parkia timoriana (DC.) Merr. & 5 & Evaluate & Data Deficient \\
\hline Asteraceae & Coreopsis tinctoria Nutt. & 4.5 & High Risk & Extirpated \\
\hline Euphorbiaceae & Synadenium grantii Hook.f. & 4 & Low Risk & Data Deficient \\
\hline Cactaceae & Peniocereus hirschtianus (K.Schum.) D.R.Hunt & 4 & Evaluate & Data Deficient \\
\hline Bignoniaceae & Radermachera sinica (Hance) Hemsl. & 4 & Evaluate & Data Deficient \\
\hline Moraceae & Antiaris toxicaria Lesch. & 3 & Evaluate & Data Deficient \\
\hline Annonaceae & Cananga odorata (Lam.) Hook.f \& Thoms & 3 & Low Risk & Data Deficient \\
\hline Euphorbiaceae & Euphorbia albomarginata Torr. \& A.Gray & 3 & Low Risk & Extirpated \\
\hline Pinaceae & Pinus jeffreyi A.Murray bis & 3 & Evaluate & Data Deficient \\
\hline Solanaceae & Solandra maxima (Sessé \& Moç.) P.S.Green & 3 & Evaluate & Data Deficient \\
\hline Moraceae & Ficus pumila $\mathrm{L}$. & 2 & Low Risk & Data Deficient \\
\hline Fabaceae & Sesbania grandiflora L. Pers. & 2 & Low Risk & Data Deficient \\
\hline Myrtaceae & Eucalyptus pulchella Desf. & 1 & Evaluate & Data Deficient \\
\hline Plantaginaceae & Linaria purpurea (L.) Mill. & 1 & High Risk & Extirpated \\
\hline Anacardiaceae & Anacardium occidentale $\mathrm{L}$. & 0 & Low Risk & Not Self-Sustaining \\
\hline Araliaceae & Plerandra elegantissima (Veitch ex Mast.) Lowry, & 0 & Low Risk & Not Self-Sustaining \\
\hline
\end{tabular}




\begin{tabular}{lcccc}
\hline \multicolumn{1}{c}{ Family } & Species Name & WRA score & WRA rating & Likely Status* \\
\hline Podocarpaceae & Afrocarpus mannii (Hook.f.) C.N.Page & -1 & Low Risk & Not Self-Sustaining \\
Marantaceae & Calathea zebrina (Hort. ex Bosse) & -1 & Low Risk & Not Self-Sustaining \\
Boraginaceae & Cordia sebestena L. & -1 & Low Risk & Not Self-Sustaining \\
Fabaceae & Delonix regia (Bojer ex Hook.) Raf.) & -1 & Low Risk & Not Self-Sustaining \\
Ebenaceae & Diospyros blancoi A.DC. & -1 & Low Risk & Not Self-Sustaining \\
Myrtaceae & Melaleuca styphelioides (Sol. ex Gaertn.) Sm. & -2 & Low Risk & Not Self-Sustaining \\
Apocynaceae & Beaumontia multiflora Teijsm. \& Binn. & -4 & Low Risk & Not Self-Sustaining \\
Magnoliaceae & Magnolia champaca (L.) Baill. ex Pierre & -5 & Low Risk & Not Self-Sustaining \\
Malvaceae & Pachira aquatica Aubl. & -6 & Low Risk & Not Self-Sustaining \\
\hline
\end{tabular}

*Species that have not been observed outside of cultivation for over 50 years are assigned a predicted status of "Extirpated" and, in all cases, they are known from less than three herbarium vouchers. Species having WRA scores $>6$ and $<1$ were assigned "Naturalised-Unspecified" and "Not Self-Sustaining", respectively, while species with scores from 1-6 were assigned "Data Deficient" (Table 2).

native flora, we propose a 7-category scheme for tracking species' statuses that largely aligns with the unified framework (Table 2). This tracking system includes the minimal number of status categories we think are critical for providing information for management decisions while accounting for common data deficiencies and ambiguities.

\section{Ambiguous alignment of questionably naturalised species}

The largest obstacle that arose when aligning the species checklist to the unified framework is that the "questionably naturalised" category contains species on fundamentally different trajectories, from species that have actually died out to those that will very soon become widespread invaders (Fig. 1). Additional field data are needed to accurately categorise them. If such surveys are not possible, an uncertainty variable, which permits categories to be assigned despite some data deficiencies, could avoid pooling species with different trajectories. However, such a scheme would still not account for species that have been introduced very recently and are just beginning to naturalise. These species do not fit into any of the naturalised categories (C3-E) because there is not yet proof that they will form self-sustaining populations in the long-term. Yet, the preceding C2 category implies that these species definitely do not form self-sustaining populations. Unlike species uncertainly aligned to status categories because population data are unknown, additional surveys will not help classify recently-introduced invaders because insufficient time has passed for that data to exist. Placing these data-deficient plants in $\mathrm{C} 2$ would remove the urgency to eradicate or at least monitor these species, even though this is precisely the group that concerns early detection and eradication programmes. Contrastingly, assigning these species to the C3 category is not a solution either because, in addition to not meeting the definition of naturalised, it could confound analyses by artificially inflating the number of naturalisations and potentially distract management towards species with less impact.

Hawai'i's checklist is not unique in having questionable status categories (Galasso et al. 2018) and similar problems distinguishing between C2 and C3 have been encountered in other applications of the unified framework to real-world scenarios 
Table 2. Practical adaptation of the unified framework requiring minimal additional data collection beyond species checklists.

\begin{tabular}{|c|c|c|c|}
\hline $\begin{array}{c}\text { Categories as per Blackburn et al. (2011), with labels in } \\
\text { brackets as per Groom et al. (2019) }\end{array}$ & \multicolumn{2}{|c|}{$\begin{array}{l}\text { Proposed Status Tracking } \\
\text { Categories }\end{array}$} & Category Description \\
\hline A - Not transported beyond limits of native range. & \multicolumn{2}{|c|}{ Not Present } & $\begin{array}{l}\text { No history of introduction, or if } \\
\text { previously introduced (e.g. for } \\
\text { cultivation or forestry), it was never } \\
\text { found outside of cultivation and is no } \\
\text { longer present. }\end{array}$ \\
\hline \multirow[t]{2}{*}{ Not Included } & \multirow[t]{2}{*}{$\begin{array}{l}\text { No Longer } \\
\text { Present* }\end{array}$} & $\begin{array}{c}\text { Establishment } \\
\text { Failure }\end{array}$ & $\begin{array}{l}\text { Previously found outside of cultivation } \\
\text { at one time, but was purposefully or } \\
\text { naturally removed before self-sustaining } \\
\text { populations formed (naturalisation). }\end{array}$ \\
\hline & & Extirpated & $\begin{array}{l}\text { Previously forming self-sustaining } \\
\text { populations (naturalised) at one } \\
\text { time, but no longer existing through } \\
\text { purposeful (eradication) or natural } \\
\text { means. }\end{array}$ \\
\hline $\begin{array}{l}\text { B1 (captive) - Individuals transported beyond limits of } \\
\text { native range, and in captivity or quarantine (i.e. individuals } \\
\text { provided with conditions suitable for them, but explicit } \\
\text { measures of containment are in place). }\end{array}$ & \multirow{2}{*}{\multicolumn{2}{|c|}{ Contained / Cultivated }} & $\begin{array}{l}\text { Existing in cultivation or somehow } \\
\text { contained. Includes accidental soil } \\
\text { contaminants that are contained within } \\
\text { pots or aquaria alongside purposefully }\end{array}$ \\
\hline $\begin{array}{l}\text { B2 (cultivated) - Individuals transported beyond limits of } \\
\text { native range and in cultivation (i.e. individuals provided } \\
\text { with conditions suitable for them, but explicit measures to } \\
\text { prevent dispersal are limited at best). }\end{array}$ & & & cultivoted speries \\
\hline $\begin{array}{l}\text { B3 (released) - Individuals transported beyond limits of } \\
\text { native range, and directly released into novel environment. }\end{array}$ & \multicolumn{2}{|c|}{ Not Included } & \multirow[t]{2}{*}{ N/A } \\
\hline $\begin{array}{l}\text { C0 (failing) - Individuals released into the wild (i.e. } \\
\text { outside of captivity or cultivation) in location where } \\
\text { introduced, but incapable of surviving for a significant } \\
\text { period. }\end{array}$ & \multicolumn{2}{|c|}{$\begin{array}{l}\text { Re-appropriated into } \\
\text { "Establishment Failure" } \\
\text { Above }\end{array}$} & \\
\hline $\begin{array}{l}\text { C1 (casual) - Individuals surviving in the wild (i.e. outside } \\
\text { of captivity or cultivation) in location where introduced, } \\
\text { no reproduction. }\end{array}$ & \multirow{2}{*}{\multicolumn{2}{|c|}{ Not Self-Sustaining }} & \multirow{2}{*}{$\begin{array}{c}\text { Plants surviving outside of cultivation } \\
\text { with sufficient evidence suggesting that } \\
\text { offspring, if produced, do not contribute } \\
\text { to a self-sustaining population. }\end{array}$} \\
\hline $\begin{array}{l}\text { C2 (reproducing) - Individuals surviving in the wild in } \\
\text { location where introduced, reproduction occurring, but } \\
\text { population not self-sustaining. }\end{array}$ & & & \\
\hline Not Included & \multicolumn{2}{|c|}{ Potentially Naturalising } & $\begin{array}{l}\text { Plants apparently surviving and } \\
\text { reproducing outside of cultivation, but } \\
\text { insufficient time has passed to determine } \\
\text { if a self-replacing population exists. }\end{array}$ \\
\hline $\begin{array}{l}\text { C3 (established) - Individuals surviving in the wild in } \\
\text { location where introduced, reproduction occurring and } \\
\text { population self-sustaining. }\end{array}$ & \multirow[t]{4}{*}{$\begin{array}{l}\text { Naturalised- } \\
\text { Unspecified }^{*}\end{array}$} & \multirow[t]{2}{*}{$\begin{array}{l}\text { Naturalised } \\
\text { Where } \\
\text { Introduced }\end{array}$} & \multirow{2}{*}{$\begin{array}{l}\text { Plants that form self-sustaining } \\
\text { populations without human } \\
\text { intervention (e.g. cultivation), but have } \\
\text { not dispersed a significant distance from } \\
\text { their point of introduction. }\end{array}$} \\
\hline $\begin{array}{l}\text { D1 (colonising) - Self-sustaining population in the wild, } \\
\text { with individuals surviving a significant distance from the } \\
\text { original point of introduction. }\end{array}$ & & & \\
\hline $\begin{array}{l}\text { D2 (invasive) - Self-sustaining population in the wild, } \\
\text { with individuals surviving and reproducing a significant } \\
\text { distance from the original point of introduction. }\end{array}$ & & \multirow{2}{*}{$\begin{array}{l}\text { Naturalised } \\
\text { Beyond } \\
\text { Introduction } \\
\text { Site }\end{array}$} & \multirow{2}{*}{$\begin{array}{l}\text { Plants that form self-sustaining } \\
\text { populations without human } \\
\text { intervention (e.g. cultivation) and } \\
\text { have dispersed and established a } \\
\text { significant distance from their point of } \\
\text { introduction. }\end{array}$} \\
\hline $\begin{array}{l}\text { E (widespread invasive) - Fully invasive species, with } \\
\text { individuals dispersing, surviving and reproducing at } \\
\text { multiple sites across a greater or lesser spectrum of habitats } \\
\text { and extent of occurrence. }\end{array}$ & & & \\
\hline
\end{tabular}

*Use if data to assign subcategories are insufficient.

(Wilson et al. 2014; Robinson et al. 2016). As discussed above, these mismatches sometimes arise from insufficient population data needed to confidently assign categories, which is common because reports of new species are often opportunistic and 
thorough surveys to delimit entire populations are rarely conducted. However, misalignments also stem from the unified framework's conceptually discrete barriers along the invasion continuum, when in reality, these boundaries are fuzzy. Moreover, the status of a species will often change over time. For instance, the unified framework acknowledges that several cycles of reproduction are necessary to form a self-sustaining population, thereby surpassing the reproduction barrier, but cannot specify how many are required. Thus, if a recently introduced species is encountered outside of cultivation and only two different life stages are visible (indicating at least one cycle of reproduction after dispersal), the self-sustainability of the population is questionable. Lack of understanding surrounding establishment success has recently been emphasised as an important factor biasing studies on geographical patterns of non-native species richness (Blackburn et al. 2020). Additionally, population sustainability is hard to predict because it depends on numerous interactions between species traits and environmental conditions and, thus, should not be assumed (Duncan et al. 2019). The hundreds of species that have been reported as "questionably naturalised" in our analysis confirm that field botanists are often plagued with uncertainty (Magona et al. 2018). This problem emphasises the need for status tracking frameworks to address uncertainty, but solutions must assess whether that uncertainty arises from insufficient data about an existing population or from insufficient time to assess the behaviour of a new species (see Probert et al. 2020 for addressing impact assessment uncertainty).

\section{WRA scores can assign a likely status for questionably naturalised species}

Our data show that the WRA can be a useful tool for predicting naturalisation, with scores obtained from the standard WRA scoring method being more able to distinguish naturalised from non-naturalised species than scores from the likelihood questions only (Fig. 2). This result was surprising because, logically, the likelihood of spread questions should more accurately reflect the propensity for plants to naturalise, whereas impact-related questions seem less relevant to predicting naturalisation. The standard WRA was also more strongly correlated with a species' tendency to naturalise across multiple islands relative to the likelihood-only score (Fig. 3). However, weak correlations for both indicate that other factors besides those accounted for in WRA scores undoubtedly influence the repeated naturalisation of these species across islands. For example, a species' ability to naturalise on multiple islands is more likely explained by deliberate or accidental between-island dispersal by humans (breaching the geographic barrier), rather than factors related to biology that are emphasised in the WRA.

Given that WRA scores appear to be more useful than scores derived from the likelihood questions only, the scoring thresholds currently in use to assess risk of weediness by the Hawai'i-Pacific WRA ( $>6$ = "High Risk", $<1$ = "Low Risk") may be sufficient for predicting the likely status of data deficient "questionably naturalised" species (Table 1). Considering that $78 \%$ of naturalised species with a WRA score over 6 are naturalised, using this threshold to predict naturalisation could lead to an error rate of up to $22 \%$. Conversely, $89 \%$ of plants with scores less than 1 were not naturalised, indicating an 
error rate of up to $11 \%$ when predicting that plants will not naturalise. Our ability to assess the WRA as a predictor of naturalisation depends on accurate categorisation of species in our test data. Undetected naturalisations or species with naturalisation potential could exist in our non-naturalised dataset (e.g. species whose establishment is limited by urban landscaping), even though rarely cultivated plants and introductions less than 20 years old were removed; this may account for the small skew towards higher scores in the distribution of non-naturalised species contributing to this error rate (Fig. 2). However, this error rate may be acceptable to invasive species managers who often err on the side of caution when identifying species likely to naturalise.

By applying the Hawai'i-Pacific WRA thresholds to "questionably naturalised" species (and accepting their associated error rates), we would infer that the 11 species $(-20 \%)$ with scores less than 1 are unlikely to naturalise and instead belong to the C1 or C2 categories, while 27 (49\%) species with scores greater than 6 would likely belong to, or eventually belong to, the $\mathrm{C} 3$ category or higher (Table 1 ). This leaves 18 species with scores ranging from 1-6 for which we are unable to infer a status category. Interestingly, scores for species not observed for more than 50 years ("possibly extirpated") ranged from 3-17; although most were predicted to naturalise, they might have existed as very small populations (making them vulnerable to stochastic extinctions) or they might be naturalised at locations rarely visited by botanists.

\section{Accommodating data deficiencies and management needs}

Similar to other inventories that reference the unified framework when categorising the status of non-native species (Wilson et al. 2014; Robinson et al. 2016; Henderson and Wilson 2017; Magona et al. 2018; Ansong et al. 2019), we found that the coarse categories typical of species checklists (e.g. cultivated, questionably naturalised and naturalised in Hawai i) did not align to all 11 categories in the unified framework. Field surveys would be needed to update existing information and, in some cases, collect new types of data, to apply some framework categories. One interpretation of this problem is that the unified framework's fine categorisation scheme cannot be realistically implemented as a tracking system for many regions, especially for developing island nations with limited funds for research and conservation (Russell et al. 2017). However, more status categories than are typically used in species checklists are needed to conduct analyses of patterns and trends to provide information for invasive species management. Accordingly, an intermediate approach is needed that avoids unrealistic requirements, such as the need for numerous site revisits over an extended time period and emphasises the use of information commonly available (e.g. occurrence reports, herbarium specimens, general survey data). To establish a tracking system based on this information, we can superimpose the unified framework's description of the invasion continuum (Blackburn et al. 2011) on to the checklist categories and the most readily attainable data (Table 2). The management goals described in the unified framework, which include prevention, eradication, containment and mitigation, help delineate a broader status categorisation scheme that still assists with management decision-making. 
When naming our proposed status categories in Table 2, we avoided the use of alpha-numerics (as are used in the unified framework) in favour of descriptive terms in order to facilitate an intuitive transition from a basic species checklist to a practical tracking system that is usable by non-specialists. To avoid confusion in terminology, our status category names are consistent with terminology used in the unified framework, as well as other publications concerning communication of biological invasions (Richardson et al. 2000; Pyšek et al. 2004; Blackburn et al. 2011). Groom et al. (2019) provide a list of terms that correspond to each of the 11 categories used in the unified framework, although we were unable to directly use those terms because our system required lumping some of the unified framework categories. We avoid using the term "invasive" as a status because it is inconsistently applied and often reserved for species that cause harm (Colautti and MacIsaac 2004; Gbedomon et al. 2020) and, unlike the biological barriers presented in the unified framework to describe a species' journey through the invasion process, harm is context dependent (e.g. impacts to biodiversity versus socio-economic resources) and cannot be conceptualised as a hurdle that must be surpassed (Blackburn et al. 2011, 2014; Bacher et al. 2018; IUCN 2020b)

We combine B1 (measures of containment in place) and B2 (containment limited) into a single category "Contained/Cultivated" because, although information about circumstances preventing dispersal can be informative for management, acquiring this data for an entire flora is difficult. Additionally, plants cultivated under strict containment measures are likely to be far less common than those with limited (or no) attempt to prevent dispersal. We include "Not Self-Sustaining" (aligning to C1-C2) and "Potentially Naturalising", with the latter referring to recently-introduced species that appear to be in the process of naturalising (but have not yet done so), which is not included as a category in the unified framework. The adoption of the latter category provides a list of species in need of careful monitoring and alerts invasive species managers to eradication possibilities without indicating that naturalisation has occurred.

Describing the phase of naturalisation for entire floras provides a unique challenge because distribution data may be insufficient to determine whether individuals are dispersing, surviving and reproducing at locations beyond introduction sites for numerous species (Blackburn et al. 2011). As a result, many checklists do not attempt to further categorise species beyond naturalisation (Uludag et al. 2017). On the other hand, data on the spread of species from known introduction sites (e.g. sites of cultivation or accidental seed contamination) may be available for well-surveyed species, especially for those that are purposefully monitored by invasive species control programmes. Our solution to this data disparity is that species should be sorted into two categories when data are available, including "Naturalised Where Introduced" and "Naturalised Beyond Introduction Site", or placed into a more general status category "NaturalisedUnspecified" (C3-E in the unified framework) if data are insufficient (Table 2). We chose to combine C3-D1 within "Naturalised Where Introduced", including naturalised plants that may or may not disperse beyond their introduction site, but where survival of dispersed offspring is not sufficient (or not yet sufficient) to form new selfsustaining populations. This phenomenon may be observed for plants that are unable to spread beyond their immediate human-disturbed surroundings (Rojas-Sandoval and 
Acevedo-Rodríguez 2015), because they are not adapted to conditions where they are dispersed. This status category contrasts with "Naturalised Beyond Introduction Site" (aligning to D2-E), which includes species known to have spread naturally beyond any possible introduction sites. Species of the former status category are likely to have localised impacts and be easier to contain or eradicate, whereas species in the latter category could potentially already have wide-ranging impacts and require substantial intervention to control or prevent further spread.

For the purposes of tracking regional floras, the A category (not transported outside native range) should be adapted to include likely invaders that have not yet arrived in the region of interest, identified via horizon scanning or risk assessment tools. Moreover, the unified framework does not categorise species that were once present in a region and are now absent, but describes the invasion continuum as a unidirectional process, with multiple avenues for invasion failure, making it unclear how species can go backwards in status. Thus, additional categories would be useful for species that were once growing outside of cultivation, but are now absent, with possible sub-categorisation according to whether a species disappeared before $(\mathrm{C} 0-\mathrm{C} 2)$ or after naturalisation ( $\geq$ C3) if data are available (Table 2). Plant eradication programmes exist on most main Hawaiian Islands, which concentrate on removing species before naturalisation or in the early stages of it (Kraus and Duffy 2010). Furthermore, several previously-naturalised species that were never targeted by weed control programmes have not been observed for numerous decades (Imada 2019) and are presumed to be naturally extirpated. In these examples, it is possible that some species were wrongly reported to be naturalised when, in fact, they failed to surpass the survival and reproduction barriers necessary to form self-sustaining populations (thus aligning to categories $\mathrm{C} 0-\mathrm{C} 2$ ), but this is now impossible to ascertain. To avoid confusion, a new category for "No Longer Present" is needed for species that were once found outside of cultivation but are not currently present (even if data are not available to accurately assess their historic status) in order to identify re-introductions and re-invasions of species that were previously thought to be extirpated (Panetta 2015).

We found that, although categories B3 (directly released outside of cultivation) and $\mathrm{C} 0$ (the same as B3 but no survival) are useful for conceptualising barriers to invasion success, they are not practically applicable as status categories (Table 2). The reason for this is that plant species encountered in the field are assumed to be surviving (and possibly reproducing) and, thus, are assumed to be at least $\mathrm{C} 1$. If plants are no longer present when sites are revisited, as would be the case for $\mathrm{C} 0$ species, which are released outside of cultivation but fail to survive, then field botanists would assume these species have become extirpated or are present in cultivation only (Table 2).

\section{Implementation and future directions}

Classification schemes used in species checklists, such as the three categories used in Hawai i's checklist, may be converted to our system using typically available information while accommodating more detailed population data when available. To account 
for uncertainty when assigning categories, we suggest that low, medium and high confidence levels be attached to each status, with guidance available in Suppl. material 1 following previous examples for categorising invasive impacts (Hawkins et al. 2015; Wilson et al. 2018). We additionally suggest that, when possible, statuses assigned with low-medium confidence be given a "likely status" using inferential tools, such as species distribution models and risk assessments (Table 2; Suppl. material 1). The likely status is not intended to be a prediction for a species' future status, but deduces its current reality, which is particularly useful for regions with numerous introductions and insufficient field monitoring, where inference may be the only method for estimating a snapshot of invasion statuses for a region's flora. In our example, analysis of field data for plants in the "questionably naturalised" checklist category can be conducted to reassign as many species as possible into a more informative status category. As we demonstrate here, WRA scores may then be used to assign a likely status of either "Not Self-Sustaining" or one of the naturalised status categories (Tables 1, 2; Suppl. material 1). Nevertheless, it is probable that further analyses and predictive tools will fail to reassign at least a few species. In our example (Table 1), we have labelled these unassignable species as having a "Data Deficient" likely status category to incentivise monitoring of these populations.

Assigning species' statuses along the introduction-naturalisation-invasion continuum is an important first step for developing a biodiversity informatics (rather than species-specific) approach to managing invasions and monitoring status changes over time. Changes in spatial extent and population size could further accompany our proposed status tracking system to strengthen assessments of both impacts and control feasibility. For instance, species that are just beginning to naturalise would be categorised as "Potentially Naturalising", a status potentially assumed to be eradicable, but feasibility may be complicated by the presence of numerous introduction sites. Future efforts towards this goal could refer to frameworks categorising commonness and changes in population size (McGeoch and Latombe 2016; Latombe et al. 2020). Tracking impacts alongside statuses and population extent would be especially useful and could be achieved by integrating the IUCN Environmental Impact Classification for Alien Taxa (EICAT; Blackburn et al. 2014; Hawkins et al. 2015; IUCN 2020b) and its socio-economic equivalent (SEICAT; Bacher et al. 2018).

Our analyses allude to possible uses of the WRA beyond the novel use we describe here, as well as its original goal of identifying potential weeds. High scoring species that have failed to naturalise are priorities for monitoring and prevention (particularly multi-island introductions) and could be compared with similarly-scored species that have naturalised, possibly identifying important traits or conditions inhibiting species otherwise prone to invade. Conversely, investigating low scoring species that have naturalised could reveal possible sources of error during prediction, suggesting location-specific contexts that promote invasion (e.g. remote island ecosystems with low native diversity). While we show that WRAs can help assign naturalised statuses for data-deficient species, future studies could investigate avenues for inferring other positions along the introduction-naturalisation-invasion continuum (Suppl. material 1). For instance, identifying extirpations is challenging because data necessary to 
establish absence are often insufficient and hence could be made easier with inferential tools. Guidance on declaring extinctions and extirpations for native species is available (IUCN 2019), but a framework that applies these principles to non-native eradications and natural extirpations is sorely needed.

\section{Conclusions}

Our attempt to apply the unified framework by Blackburn et al. (2011) to Hawai' $\mathrm{i}$ revealed its limitations as a tracking system for entire non-native floras. Specifically, the unified framework does not address species that have uncertain statuses, which are common surrounding the early stages of naturalisation. However, our findings indicate that this issue can be resolved for many species by predicting a likely status using WRA scores. We therefore demonstrate that species tracking systems and predictive tools like WRA should be integrated to strengthen their ability to inform management of already-introduced plant species. We further propose a system for tracking entire floras that accommodates real-world data while retaining categories relevant to invasive plant managers. Our system is particularly useful for invader-rich floras, such as those common on islands, where a mix of on-the-ground information and methods to address data gaps are necessary to solve real-world biosecurity dilemmas.

\section{Acknowledgements}

We thank reviewers Wayne Dawson, Nicol Fuentes and Annie Simpson whose comments helped improve this manuscript, as well as John Wilson for his useful suggestions during the editorial process and comments arising from a workshop on 'Frameworks used in Invasion Science' hosted by the DSI-NRF Centre of Excellence for Invasion Biology in Stellenbosch, South Africa, 11-13 November 2019, that was supported by the National Research Foundation of South Africa and Stellenbosch University. Additionally, we are indebted to Clyde Imada for his careful curation of Hawai 'i's naturalised plant checklist and for sharing his thoughts on a tracking system and to Chuck Chimera for his guidance on the Hawai' i-Pacific Weed Risk Assessment.

We thank the Hawai' $i$ Invasive Species Council for providing the funding support to conduct this work.

\section{References}

Ansong M, Pergl J, Essl F, Hejda M, van Kleunen M, Randall R, Pyšek P (2019) Naturalized and invasive alien flora of Ghana. Biological Invasions 21: 669-683. https://doi. org/10.1007/s10530-018-1860-7

Bacher S, Blackburn TM, Essl F, Genovesi P, Heikkilä J, Jeschke JM, Jones G, Keller R, Kenis M, Kueffer C, Martinou AF, Nentwig W, Pergl J, Pyšek P, Rabitsch W, Richardson DM, Roy 
HE, Saul W-C, Scalera R, Vilà M, Wilson JRU, Kumschick S (2018) Socio-economic impact classification of alien taxa (SEICAT). Methods in Ecology and Evolution 9: 159-168. https://doi.org/10.1111/2041-210X.12844

Blackburn TM, Cassey P, Duncan RP (2020) Colonization pressure: a second null model for invasion biology. Biological Invasions 22: 1221-1233. https://doi.org/10.1007/s10530019-02183-7

Blackburn TM, Essl F, Evans T, Hulme PE, Jeschke JM, Kuhn I, Kumschick S, Markova Z, Mrugala A, Nentwig W, Pergl J, Pysek P, Rabitsch W, Ricciardi A, Richardson DM, Sendek A, Vila M, Wilson JRU, Winter M, Genovesi P, Bacher S (2014) A unified classification of alien species based on the magnitude of their environmental impacts. PLoS Biology 12: 11. https://doi.org/10.1371/journal.pbio.1001850

Blackburn TM, Pyšek P, Bacher S, Carlton JT, Duncan RP, Jarošík V, Wilson JRU, Richardson DM (2011) A proposed unified framework for biological invasions. Trends in Ecology \& Evolution 26: 333-339. https://doi.org/10.1016/j.tree.2011.03.023

Colautti RI, MacIsaac HJ (2004) A neutral terminology to define "invasive" species. Diversity and Distributions 10: 135-141. https://doi.org/10.1111/j.1366-9516.2004.00061.x

Cooney R (2004) The precautionary principle in biodiversity conservation and natural resource management: an issues paper for policy-makers, researchers and practitioners. In: IUCN Policy and Global Change Series No. 2. IUCN: Gland, Switzerland, Cambridge, UK, 51 pp.

Daehler CC, Denslow JS, Ansari S, Kuo H-C (2004) A risk-assessment system for screening out invasive pest plants from Hawaii and other pacific islands. Conservation Biology 18: 360-368. https://doi.org/10.1111/j.1523-1739.2004.00066.x

Daehler CC, Virtue JG (2010) Likelihood and consequences: reframing the Australian weed risk assessment to reflect a standard model of risk. Plant Protection Quarterly 25: 52-55.

Danihelka J, Chrtek Jr J, Kaplan Z (2012) Checklist of vascular plants of the Czech Republic. Preslia 84: 647-811. http://www.preslia.cz/P123Danihelka.pdf

Duncan RP, Cassey P, Pigot AL, Blackburn TM (2019) A general model for alien species richness. Biological Invasions 21: 2665-2677. https://doi.org/10.1007/s10530-019-02003-y

Galasso G, Conti F, Peruzzi L, Ardenghi NMG, Banfi E, Celesti-Grapow L, Albano A, Alessandrini A, Bacchetta G, Ballelli S, Mazzanti MB, Barberis G, Bernardo L, Blasi C, Bouvet D, Bovio M, Cecchi L, Guacchio ED, Domina G, Fascetti S, Gallo L, Gubellini L, Guiggi A, Iamonico D, Iberite M, Jiménez-Mejías P, Lattanzi E, Marchetti D, Martinetto E, Masin RR, Medagli P, Passalacqua NG, Peccenini S, Pennesi R, Pierini B, Podda L, Poldini L, Prosser F, Raimondo FM, Roma-Marzio F, Rosati L, Santangelo A, Scoppola A, Scortegagna S, Selvaggi A, Selvi F, Soldano A, Stinca A, Wagensommer RP, Wilhalm T, Bartolucci F (2018) An updated checklist of the vascular flora alien to Italy. Plant Biosystems - An International Journal Dealing with all Aspects of Plant Biology 152: 556-592. https://doi. org/10.1080/11263504.2018.1441197

Gbedomon RC, Salako VK, Schlaepfer MA (2020) Diverse views among scientists on nonnative species. NeoBiota 54: 49-69. https://doi.org/10.3897/neobiota.54.38741

Gilbert B, Levine JM (2013) Plant invasions and extinction debts. Proceedings of the National Academy of Sciences 110: 1744-1749. https://doi.org/10.1073/pnas.1212375110

Groom Q, Desmet P, Reyserhove L, Adriaens T, Oldoni D, Vanderhoeven S, Baskauf SJ, Chapman A, McGeoch M, Walls R, Wieczorek J, Wilson J, Zermoglio PF, Simpson A 
(2019) Improving Darwin Core for research and management of alien species. Biodiversity Information Science and Standards 3: e38084. https://doi.org/10.3897/biss.3.38084

Hawkins CL, Bacher S, Essl F, Hulme PE, Jeschke JM, Kühn I, Kumschick S, Nentwig W, Pergl J, Pyšek P, Rabitsch W, Richardson DM, Vilà M, Wilson JRU, Genovesi P, Blackburn TM (2015) Framework and guidelines for implementing the proposed IUCN Environmental Impact Classification for Alien Taxa (EICAT). Diversity and Distributions 21: 1360-1363. https://doi.org/10.1111/ddi.12379

Henderson L, Wilson JRU (2017) Changes in the composition and distribution of alien plants in South Africa: An update from the Southern African Plant Invaders Atlas. Bothalia 47: 26. https://doi.org/10.4102/abc.v47i2.2172

HPWRA (2019) Hawaii-Pacific Weed Risk Assessment. https://www.hpwra.org [Accessed October 2019]

Hulme PE (2006) Beyond control: wider implications for the management of biological invasions. Journal of Applied Ecology 43: 835-847. https://doi.org/10.1111/j.1365-2664.2006.01227.x Imada CT (2012) Hawaiian native and naturalized vascular plant checklist. Bishop Museum Technical Report 60: 29 pp. [+ 27 appendices]

Imada CT (2019) Hawaiian naturalized vascular plant checklist. Bishop Museum Technical Report 69: 23 pp.

Imada CT, Staples GW, Herbst DR (2000) Annotated checklist of cultivated plants of Hawaii, Bernice Pauahi Bishop Museum. http://www2.bishopmuseum.org/HBS/botany/cultivatedplants [Accessed November 2018]

IUCN (2019) Guidelines for Using the IUCN Red List Categories and Criteria. Version 14. http://www.iucnredlist.org/documents/RedListGuidelines.pdf

IUCN (2020a) The IUCN Red List of Threatened Species. Version 2020-1. https://www.iucnredlist.org [Accessed June 2020]

IUCN (2020b) IUCN EICAT Categories and Criteria. The Environmental Impact Classification for Alien Taxa (EICAT). First edition. IUCN, Gland, Switzerland and Cambridge. https://doi.org/10.2305/IUCN.CH.2020.05.en

Jacobs L, Richardson D, Lepschi B, Wilson J (2017) Quantifying errors and omissions in alien species lists: The introduction status of Melaleuca species in South Africa as a case study. NeoBiota 32: 89-105. https://doi.org/10.3897/neobiota.32.9842

Kier G, Kreft H, Lee TM, Jetz W, Ibisch PL, Nowicki C, Mutke J, Barthlott W (2009) A global assessment of endemism and species richness across island and mainland regions. Proceedings of the National Academy of Sciences of the United States of America 106: 9322-9327. https://doi.org/10.1073/pnas.0810306106

Komsta L (2019) mblm: Median-Based Linear Models. R package version 0.12.1. https:// CRAN.R-project.org/package $=\mathrm{mblm}$

Kraus F, Duffy DC (2010) A successful model from Hawaii for rapid response to invasive species. Journal for Nature Conservation 18: 135-141. https://doi.org/10.1016/j.jnc.2009.07.001 Kueffer C, Daehler CC, Torres-Santana CW, Lavergne C, Meyer JY, Otto R, Silva L (2010) A global comparison of plant invasions on oceanic islands. Perspectives in Plant Ecology Evolution and Systematics 12: 145-161. https://doi.org/10.1016/j.ppees.2009.06.002 
Kueffer C, Loope L (2009) Prevention, early detection and containment of invasive, non-native plants in the Hawaiian Islands: current efforts and needs. Honolulu (HI): Pacific Cooperative Studies Unit, University of Hawaii at Manoa, Department of Botany. PCSU Technical Report, 166. http://hdl.handle.net/10125/26984

Kuussaari M, Bommarco R, Heikkinen RK, Helm A, Krauss J, Lindborg R, Öckinger E, Pärtel M, Pino J, Rodà F, Stefanescu C, Teder T, Zobel M, Steffan-Dewenter I (2009) Extinction debt: a challenge for biodiversity conservation. Trends in Ecology \& Evolution 24: 564-571. https://doi.org/10.1016/j.tree.2009.04.011

Larrue S, Butaud JF, Daehler CC, Ballet S, Chadeyron J, Oyono R (2018) Persistence at the final stage of volcanic island ontogeny: Abiotic predictors explain native plant species richness on 111 remote Pacific atolls. Ecology and Evolution 8: 12208-12220. https://doi.org/10.1002/ece3.4680

Latombe G, Essl F, McGeoch MA (2020) The effect of cross-boundary management on the trajectory to commonness in biological invasions. In: Wilson JR, Bacher S, Daehler CC, Groom QJ, Kumschick S, Lockwood JL, Robinson TB, Zengeya TA, Richardson DM (Eds) Frameworks used in Invasion Science. NeoBiota 62: 241-267. https://doi. org/10.3897/neobiota.62.52708

Lonsdale WM (1999) Global Patterns of Plant Invasions and the Concept of Invasibility. Ecology 80: 1522-1536. https://doi.org/10.1890/0012-9658(1999)080[1522:GPOPIA]2.0.CO;2

Magona N, Richardson DM, Roux JJL, Kritzinger-Klopper S, Wilson JRU (2018) Even wellstudied groups of alien species might be poorly inventoried: Australian Acacia species in South Africa as a case study. NeoBiota 39: 1-29. https://doi.org/10.3897/neobiota.39.23135

McGeoch MA, Latombe G (2016) Characterizing common and range expanding species. Journal of Biogeography 43: 217-228. https://doi.org/10.1111/jbi.12642

Nelson RE, Schubert TH (1976) Adaptability of selected tree species planted in Hawaii forests. U.S. Department of Agriculture Forest Service Resource Bulletin, Berkeley, California, 22 pp. https://doi.org/10.5962/bhl.title.100144

Palmer DD (2003) Hawai'i's ferns and fern allies. Honolulu, University of Hawaii Press.

Panetta FD (2015) Weed eradication feasibility: lessons of the $21^{\text {st }}$ century. Weed Research 55: 226-238. https://doi.org/10.1111/wre.12136

Price JP, Wagner WL (2018) Origins of the Hawaiian flora: Phylogenies and biogeography reveal patterns of long-distance dispersal. Journal of Systematics and Evolution 56: 600-620. https://doi.org/10.1111/jse.12465

Probert AF, Volery L, Kumschick S, Vimercati G, Bacher S (2020) Understanding uncertainty in the Impact Classification for Alien Taxa (ICAT) assessments. In: Wilson JR, Bacher S, Daehler CC, Groom QJ, Kumschick S, Lockwood JL, Robinson TB, Zengeya TA, Richardson DM (Eds) Frameworks used in Invasion Science. NeoBiota 62: 387-405. https:// doi.org/10.3897/neobiota.62.52010

Pyšek P, Pergl J, Essl F, Lenzner B, Dawson W, Kreft H, Weigelt P, Winter M, Kartesz J, Nishino M, Antonova LA, Barcelona JF, Cabezas FJ, Cardenas D, Cardenas-Toro J, Castano N, Chacon E, Chatelain C, Dullinger S, Ebel AL, Figueiredo E, Fuentes N, Genovesi P, Groom QJ, Henderson L, Inderjit, Kupriyanov A, Masciadri S, Maurel N, Meerman J, Morozova O, Moser D, Nickrent D, Nowak PM, Pagad S, Patzelt A, Pelser PB, Seebens H, Shu WS, Thomas J, Velayos M, Weber E, Wieringa JJ, Baptiste MP, van Kleunen M (2017) Naturalized alien flora of the 
world: species diversity, taxonomic and phylogenetic patterns, geographic distribution and global hotspots of plant invasion. Preslia 89: 203-274. https://doi.org/10.23855/preslia.2017.203

Pyšek P, Richardson DM, Rejmanek M, Webster GL, Williamson M, Kirschner J (2004) Alien plants in checklists and floras: towards better communication between taxonomists and ecologists. Taxon 53: 131-143. https://doi.org/10.2307/4135498

Pyšek P, Sádlo J, Mandák B (2002) Catalogue of alien plants of the Czech Republic. Preslia 74: 97-186.

Ranker TA (2016) What do we know about Hawaiian ferns and lycophytes? Journal of Systematics and Evolution 54: 626-637. https://doi.org/10.1111/jse.12213

Richardson DM, Pyšek P, Rejmánek M, Barbour MG, Panetta FD, West CJ (2000) Naturalization and invasion of alien plants: concepts and definitions. Diversity and Distributions 6: 93-107. https://doi.org/10.1046/j.1472-4642.2000.00083.x

Robinson TB, Alexander ME, Simon CA, Griffiths CL, Peters K, Sibanda S, Miza S, Groenewald B, Majiedt P, Sink KJ (2016) Lost in translation? Standardising the terminology used in marine invasion biology and updating South African alien species lists. African Journal of Marine Science 38: 129-140. https://doi.org/10.2989/181423 2X.2016.1163292

Rojas-Sandoval J, Acevedo-Rodríguez P (2015) Naturalization and invasion of alien plants in Puerto Rico and the Virgin Islands. Biological Invasions 17: 149-163. https://doi. org/10.1007/s10530-014-0712-3

Russell JC, Meyer JY, Holmes ND, Pagad S (2017) Invasive alien species on islands: impacts, distribution, interactions and management. Environmental Conservation 44: 359-370. https://doi.org/10.1017/S0376892917000297

Sax DF, Gaines SD (2008) Species invasions and extinction: The future of native biodiversity on islands. Proceedings of the National Academy of Sciences of the United States of America 105: 11490-11497. https://doi.org/10.1073/pnas.0802290105

Sen PK (1968) Estimates of the regression coefficient based on Kendall's tau. Journal of the American Statistical Association 63 (324): 1379-1389. https://doi.org/10.1080/016214 59.1968.10480934

Skolmen RG (1980) Plantings on the forest reserves of Hawaii 1910-1960. Honolulu.

Staples G, Herbst DR (2005) A tropical garden flora: plants cultivated in the Hawaiian Islands and other tropical places. Honolulu, Bishop Museum Press. 908 pp.

Uludag A, Aksoy N, Yazlık A, Arslan ZF, Yazmış E, Uremis I, Cossu TA, Groom Q, Pergl J, Pyšek P, Brundu G (2017) Alien flora of Turkey: checklist, taxonomic composition and ecological attributes. NeoBiota 35: 61-85. https://doi.org/10.3897/neobiota.35.12460

Virtanen P, Gommers R, Oliphant TE, Haberland M, Reddy T, Cournapeau D, Burovski E, Peterson P, Weckesser W, Bright J, van der Walt SJ, Brett M, Wilson J, Jarrod Millman K, Mayorov N, Nelson ARJ, Jones E, Kern R, Larson E, Carey CJ, Polat I, Feng Y, Moore EW, Vanderplas J, Laxalde D, Perktold J, Cimrman R, Henriksen I, Quintero EA, Harris CR, Archibald AM, Ribeiro AH, Pedregosa F, van Mulbregt P, SciPy 1.0 Contributors (2020) SciPy 1.0: fundamental algorithms for scientific computing in Python. Nature Methods 17: 261-272. https://doi.org/10.1038/s41592-019-0686-2 
Wagner WL, Herbst DR, Sohmer SH (1999) Manual of the Flowering Plants of Hawai'i, revised ed. Bishop Museum Special Publication 97. Honolulu, University of Hawai'i Press. 1918 pp.

Waskom M, Botvinnik O, Ostblom J, Lukauskas S, Hobson P, Gelbart M, Gemperline DC, Augspurger T, Halchenko Y, Cole JB, Warmenhoven J, de Ruiter J, Pye C, Hoyer S, Vanderplas J, Villalba S, Kunter G, Quintero E, Bachant P, Martin M, Meyer K, Swain C, Miles A, Brunner T, O’Kane D, Yarkoni T, Williams ML, Evans C (2020) mwaskom/seaborn: v0.10.1. Zenodo. Wilcox RR (2010) Theil-Sen estimator. In: Fundamentals of Modern Statistical Methods: Substantially Improving Power and Accuracy ( $2^{\text {nd }}$ edn.). Berlin, Springer-Verlag, 207-210. Wilson JRU, Caplat P, Dickie IA, Hui C, Maxwell BD, Nuñez MA, Pauchard A, Rejmánek M, Richardson DM, Robertson MP, Spear D, Webber BL, van Wilgen BW, Zenni RD (2014) A standardized set of metrics to assess and monitor tree invasions. Biological Invasions 16: 535-551. https://doi.org/10.1007/s10530-013-0605-x

Wilson JRU, Faulkner KT, Rahlao SJ, Richardson DM, Zengeya TA, van Wilgen BW (2018) Indicators for monitoring biological invasions at a national level. Journal of Applied Ecology 55(6): 2612-2620. https://doi.org/10.1111/1365-2664.13251

\section{Supplementary material I}

Guidance on the status confidence rating and adapting a regional checklist to track invasion statuses

Authors: Kelsey C. Brock, Curtis C. Daehler

Data type: table and figure

Copyright notice: This dataset is made available under the Open Database License (http://opendatacommons.org/licenses/odbl/1.0/). The Open Database License $(\mathrm{ODbL})$ is a license agreement intended to allow users to freely share, modify, and use this Dataset while maintaining this same freedom for others, provided that the original source and author(s) are credited.

Link: https://doi.org/10.3897/neobiota.62.52764.suppl1 